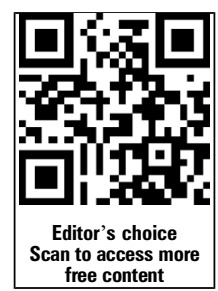

${ }^{1}$ Department of Athletic Medicine, University Health Services, Princeton University, Princeton, New Jersey, USA ${ }^{2}$ Rutgers-Robert Wood Johnson Medical School, University Health Services, Princeton University, Princeton New Jersey, USA

\section{Correspondence to} Dr Margot Putukian, Department of Athletic Medicine, University Health Services, Princeton University, Princeton, NJ 08540, USA; putukian@Princeton.edu

Accepted 25 November 2015 Published Online First 30 December 2015

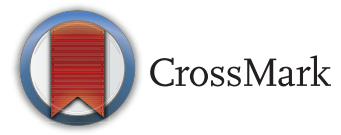

To cite: Putukian M. $\mathrm{Br} J$ Sports Med 2016:50: 145-148.

\title{
The psychological response to injury in student athletes: a narrative review with a focus on mental health
}

\author{
Margot Putukian ${ }^{1,2}$
}

\begin{abstract}
Background Injury is a major stressor for athletes and one that can pose significant challenges. Student athletes must handle rigorous academic as well as athletic demands that require time as well as significant physical requirements. Trying to perform and succeed in the classroom and on the playing field has become more difficult as the demands and expectations have increased. If an athlete is injured, these stressors increase.

Main thesis Stress is an important antecedent to injuries and can play a role in the response to, rehabilitation and return to play after injury. The psychological response to injury can trigger and/or unmask mental health issues including depression and suicidal ideation, anxiety, disordered eating, and substance use/abuse. There are barriers to mental health treatment in athletes. They often consider seeking help as a sign of weakness, feeling that they should be able to 'push through' psychological obstacles as they do physical ones. Athletes may not have developed healthy coping behaviours making response to injury especially challenging.

Purpose I discuss the current state of knowledge regarding the psychological response to injury and delineate resources necessary to direct the injured athlete to a mental health care provider if appropriate.
\end{abstract}

\section{INTRODUCTION}

Whether participation in sport is protective or harmful to mental health remains unclear. Though exercise and participation in sport is generally favourable, improving mood and self-esteem, at the extremes of exercise we see increased stress and burnout and the potential for adverse effects. ${ }^{1-5}$ Growing research is dedicated to understanding the relationship between exercise and mental health disorders ${ }^{1}$ as well as to chronic stress and mental health. ${ }^{6}$ Mental health concerns such as eating disorders, depression and suicide, anxiety, gambling and substance use are among the most important in college-aged students, both athletes and nonathletes. $^{7-12}$ Some data exist that certain concerns, such as performance anxiety, eating disorders and binge drinking may be more common in athletes than their non-athletic peers. ${ }^{13-15}$ Symptoms of depression are not uncommon in athletes ${ }^{16}{ }^{17}$ and in one study symptoms were reported in $21 \%$ of collegiate athletes with women, freshman and those that self-reported pain had a significantly increased risk for reporting depressive symptoms. ${ }^{16}$ Depression in some athletes may also be related with performance failure, and elite athletes may be at a greater risk for depression than less elite athletes. ${ }^{18}$

\section{INJURIES: ANTECEDENTS AND THE EMOTIONAL RESPONSE}

Injuries are common in athletes and the psychological response to injury can include normal as well as problematic responses,. ${ }^{19-22}$ Preinjury factors, including biological, physical, psychological sociocultural, and most importantly stress, can increase an athlete's risk of injury and poor recovery. ${ }^{19-23}$ After injury, several factors such as cognition, affect and behaviour are all inter-related and can also affect each other in the short and long term. ${ }^{21}$

Stress can cause attentional changes, distraction and increased self-consciousness that all can interfere with performance and predispose an athlete to injury. $^{20212425}$ Chronic stress increases hair cortisol levels in a wide range of contexts/situations such as endurance athletes and pain as well as in patients with major depression. ${ }^{6}$ Stress increases muscle tension and coordination that can increase the risk for injury; decreasing stress can actually decrease injury and illness rates. ${ }^{20} 242627$

Adolescents who have 'high mental toughness' were more resilient to stress and reported a lower number of depressive symptoms. ${ }^{28}$ Adolescents with higher 'resilience' scores predicted lower scores on levels of depression, anxiety, stress and obsessive-compulsive symptoms after controlling for age and sex. ${ }^{29}$ This underscores the importance of identifying which stressors apply to student athletes in general as well as which are at play in individual athlete and are modifiable. These data also emphasise the importance of considering stress reduction techniques in an attempt to decrease the risk for injury and improve performance.

Physical injury can trigger depression as well as other problematic responses. ${ }^{30-32}$ In a retrospective study of Division I football players, 33\% of injured athletes reported high levels of depressive symptoms, using the Center for Epidemiological Studies Depression scale, compared with $27 \%$ of noninjured athletes. ${ }^{30}$ Depressed athletes and those under 'stress' are at an increased risk for injury, and athletic performance is often impacted by emotional or mental health factors. ${ }^{20}$ When an athlete is injured there is a normal emotional reaction that includes processing the medical information about the injury provided by the medical team and coping emotionally with the injury. Emotional responses are listed in box 1 .

Athletes differ in their response to injury. The response to injury extends from the time 
Box 1 Emotional response to injury (modified from American College of Sports Medicine et $a^{20}$ )

Sadness
Isolation
Irritation
Lack of motivation
Anger
- Crustration
Changes in appetite
- Sleep disturbance
Disengagement

immediately after injury through to the postinjury phase and then rehabilitation and ultimately with return to activity. For the majority of injuries and illness return to preinjury levels of activity occur. With more serious illness or injury, a career ending injury is possible, and the health care provider should be prepared to address these issues. The Team Physician is ultimately responsible for the return to play decision and addressing psychological issues is a very important component of this decision. ${ }^{33} 34$

\section{INJURIES: PROBLEMATIC RESPONSES}

Athletic trainers, team physicians as well as athletes, coaches and administrators must understand that emotional reactions to injury are normal, but problematic reactions are those that either do not resolve, worsen over time or where the severity of symptoms seem excessive. ${ }^{20} 35$ Problematic emotional reactions are listed in box 2 .

Examples of problematic reactions include injured athletes who restrict their caloric intake because they feel since they are injured they 'don't deserve' to eat, with the restrictive eating then triggering disordered eating. In an athlete already at risk for disordered eating patterns and eating disorders, injury can increase the vulnerability to this problematic response.

Another problematic response to injury is depression. It can be a significant warning sign as it can magnify other responses and can also impact recovery from injury.

Box 2 Problematic emotional reactions (modified from American College of Sports Medicine et $a^{20}$ )

Persistent symptoms

- Alterations of appetite

- Sleep disturbance

- Irritability

Worsening symptoms

- Alterations of appetite leading to disordered eating

- Sadness leading to depression

- Lack of motivation leading to apathy

- Disengagement leading to alienation

Excessive symptoms

- Pain behaviours

- Excessive anger or rage

- Frequent crying or emotional outbursts

- Substance abuse
Substance use and abuse is a common problematic response and different substances are often used as a method of modulating emotions. For example; cocaine is used to provide stimulation and modify depression, and alcohol is often used to counter mania. Alcohol as well as other recreational drugs or prescription narcotics are often used to self-medicate in an attempt to improve mood in depression.

Gambling and legal problems or fighting are also problematic responses that occur in student athletes, and it is important to understand that it is not infrequent to have several problematic responses occurring concurrently, such as alcohol abuse and depression, depression and eating disorders and alcohol and fighting. ${ }^{10-13} 15-182036$

In a review of depression and alcohol use in 262 collegiate athletes, ${ }^{36} 21 \%$ reported high alcohol use and problems associated with alcohol. There was a correlation between selfreported symptoms of depression and alcohol abuse. Those athletes with severe depression and psychological symptoms had a significantly greater rate of alcohol abuse than those with low depression and low psychological symptoms. Furthermore, in a review of five collegiate athletes who completed suicide, common factors included (1) considerable success before injury, (2) serious injury requiring surgery (3) long rehabilitation with restriction from play (4) inability to return to the prior level of play and (5) being replaced in their position by a teammate. ${ }^{37}$ Of these the greatest predictor was the severity of injury. Other risk factors, such as stressful life events (including injury), chronic mental illness, personality traits with maladjustment, family history of suicidal tendency and psychiatric disorder /other issues (eg, homosexuality, drug use, previous suicide attempts, chronic low self-esteem) were overlapping risk factors.

After a significant time loss injury, athletes can suffer physically as well as emotionally with a decrease in quality of life measures. ${ }^{38} 39$ The emotional response to an ACL injury can be more significant than that experienced after concussion. ${ }^{40}$ When Olympic skier Picabo Street sustained significant leg and knee injuries in March of 1998, she battled significant depression during her recovery. She stated "I went through a huge depression. I went all the way to rock bottom. I never thought that I would ever experience anything like that in my life. I think it was a combination of the atrophying of my legs, the new scars, and feeling like a caged animal" ${ }^{41}$ She ultimately received treatment and returned to skiing before retiring. Kenny McKinley played as a wide receiver professionally for the Denver Broncos Football team. He was found dead of a self-inflicted gunshot wound in September of 2010, after growing despondent after a knee injury. He had undergone surgery expected to sideline for a season and had made statements about being unsure what he would do without football and reportedly sharing thoughts that he should kill himself. ${ }^{41}$ These case examples demonstrate how injury can often trigger significant depression and suicidal ideation.

Concussion can be particularly challenging for student athletes to handle emotionally, increasingly common in a variety of contact and collision sports; an injury that is occasionally associated with significant time loss or retirement from sport. ${ }^{42-46}$ For the athlete with a severe knee injury, such as an ACL tear requiring surgery, one can often provide a predictable timeline and modified exercise (swimming or biking) options early in recovery. Concussion is difficult because a discrete timeline for recovery and return to play is unknown. In addition, the initial management of concussion includes cognitive and physical rest and the latter is something that many athletes often depend on to handle stressors. They are not able to exercise, and given the 
emotional and cognitive symptoms associated with concussion, often also struggle with academics as well as the emotional response to injury. In addition, depression and anxiety are felt to be modifiers of concussive injury, further prolonging recovery from injury. ${ }^{43} 47$ There is limited data to suggest an increased incidence of depression in athletes with a higher history of selfreported concussion. ${ }^{48}{ }^{49}$ For the concussed athlete it is especially important to watch for problematic response from injury as well as understand the resources for treatment. Finally, with the recent description of chronic traumatic encephalopathy (CTE), with as of yet significantly more unknown than known, ${ }^{50-52}$ athletes are often concerned that they may develop CTE even after a mild concussive injury. This fear for what might occur in the future amplifies the importance of recognising and managing concussive injury and addressing these concerns.

\section{OBSTACLES TO SEEKING CARE}

There are several obstacles to seeking care for mental health issues in athletes. It is important to understand that athletes are less likely to seek help for mental health issues than nonathletes. ${ }^{53}{ }^{54}$ For college mental health service providers it is also important to understand that student athletes are often a unique population with specific obstacles to seeking care. Accessibility is important often there is a 'teaching moment' where getting an athlete to consider treatment can be challenging and therefore expediting an evaluation can be essential. It is also important to realise that privacy issues can be different; coaches, athletic trainers and team physicians often play an important role in the support network for the athlete. Including these providers in the discussion of significant issues can be helpful in providing care to the athlete.

Athletes may be at greater risk for mental health issues in that they are less likely to seek treatment, may be afraid to reveal symptoms, may see seeking counselling as a sign of weakness, are accustomed to working through pain, may have a sense of entitlement and never had to struggle, and/or may not have developed healthy coping mechanisms to deal with failure. In addition, many athletes have not developed their identity outside of that as an athlete and therefore if this role is threatened by injury or illness, they may experience a significant 'loss'. As discussed previously, exercise is often an escape or coping mechanism for many athletes, so if injury occurs and they cannot exercise, it can result in a problematic response.

There remains a stigma surrounding seeking mental health services for athletes and of all the obstacles for seeking care, this may be the most important. In a study of elite athletes aged 1623 , focus group discussions demonstrated that stigma was the most important perceived barrier to seeking help, along with a lack of mental health literacy, and negative past experiences of help-seeking. ${ }^{54}$ This study also demonstrated that encouragement from others, having an established relationship with a provider, a positive previous interaction with providers, internet access and the positive attitudes of others, especially coaches, all facilitated help seeking. ${ }^{53}$ Barriers and facilitators for helpseeking identified in this study are listed in box 3 .

\section{FACILITATING TREATMENT AND SUPPORT}

As an athletic trainer, team physician or other healthcare provider, it is important to recognise the common signs and symptoms for various mental health concerns and understand the resources available for treatment and management. ${ }^{55-59}$ It is a responsibility of the athletic trainer and team physician to do everything possible to 'demystify' mental health concerns and help athletes understand that mental health concerns are as
Box 3 Barriers and facilitators to help seeking (modified from Gulliver et $\left.a\right|^{54}$ )

Barriers (ranked from most common to least, top to bottom)

- Stigma

- Lack of problem awareness

- Difficulty in or not willing to express emotion

- Lack of time

- Denial of problem

- Not sure who to ask for help

- Fear of what might happen

- Worried about affecting ability to play / train

- Belief that it would not help

- Not accessible

Facilitators

- Education and awareness of mental health issues and/or services

- Social support

- Encouragement from others

- Accessibility (eg, money, transport, location)

- Positive relationship with service staff

- Confidentiality

- Time

- Integration into athlete life

- Positive past experiences

- Ease of expressing emotion and openness

important to recognise and treat as other medical and musculoskeletal issues. Underscoring the availability of athletic medicine staffs to provide early referral and management of mental health concerns is essential.

Also essential is a basic understanding of what measures can make a difference in terms of treating mental health concerns as well as improving general wellness and performance. ${ }^{20} 55-59$ Treatment that can improve resilience and mental toughness can be expected to help mitigate stress and potentially minimise depressive symptoms. ${ }^{28}$ A systematic review evaluated 983 athletes and 15 psychological factors identified that three psychological elements (self-determination theory-autonomy, competence and relatedness) as the factors most important in positive rehabilitation and return to preinjury level of play. ${ }^{34}$ In addition, another study demonstrated that there may be a role for internet-based interventions in demystifying mental health issues and providing education regarding common signs and symptoms as well as the benefits for seeking help. ${ }^{53}$

It is important for coaches, athletic trainers and team physicians to provide support for injured athletes and keep athletes involved and part of the team. This might include keeping athletes engaged and encouraging athletes to seek help instead of 'tough it out'. For coaches one of the most powerful actions is to 'give the athlete permission' and encourage them to seek care. ${ }^{53}$ Having programmes available to educate athletes as well as athletic medicine and administrative staffs regarding the resources available and the importance of collaborative programming is helpful in providing care. ${ }^{20} 2155-58$ 60-62

Including screening questions during the preparticipation examination and interim physicals performed at the high school and college level that address mental health concerns is an opportunity to detect issues early. ${ }^{55-57}$ Considering more comprehensive questionnaires such as the Generalized Anxiety Disorder screen $(G A D-7)^{63}$ and the Patient Health 
Questionnaire (PHQ-9) ${ }^{64}$ as a screen for anxiety and depression, respectively, may be useful at baseline as well as during return to activity. ${ }^{65}$ In addition, by including these measures as part of the sports physical, it can normalise mental health issues as important and potentially decrease the stigma for discussing these issues.

\section{FUTURE DIRECTIONS/CONCLUSIONS}

Injury is a stressor that has physical as well as psychological responses. The psychological response to injury is important and although emotional responses to injury are common, problematic responses can be those that are persistent, worsen or appear excessive. At times, problematic responses can trigger more serious mental health issues including depression, anxiety, eating disorders, substance use.

There are obstacles to treatment of mental health concerns in athletes, and athletic trainers, team physicians and other healthcare providers play an essential role in recognising and identifying athletes at risk for mental health concerns. Having a comprehensive plan in place to screen for, detect and manage student athletes with problematic response to injury is important. Several positive coping mechanisms and interventions can help to manage the student athlete with problematic responses. Understanding the mental health resources available, making timely referrals, and providing support for help-seeking behaviours are essential for the sports medicine team.

Contributors This article was planned and completed by the sole author, MP.

Competing interests None declared.

Provenance and peer review Not commissioned; externally peer reviewed.

\section{REFERENCES}

1 Matta Mello Portugal E, Cevada T, Sobral Monteiro-Junior R, et al. Neuroscience of exercise: from neurobiology mechanisms to mental health. Neuropsychobiology 2013;68:1-14.

2 Schulz KH, Meyer A, Langguth N. Exercise and psychological well-being Bundesgundheitsforschung Gesundheitsschutz 2012;55:55-65.

3 Snyder AR, Martinez JC, Bay RC. Health-related quality of life differs between adolescent athletes and adolescent non-athletes. J Sport Rehabil 2010;19:237-48.

4 Armstrong S, Oomen-Early J. Social connectedness, self-esteem, and depression symptomatology among collegiate athletes versus non-athletes. J Am Coll Health 2009;57:521-6.

5 Kellman M. Preventing overtraining in athletes in high-intensity sports and stress/ recovery monitoring. Scand J Med Sci Sports 2010;20(Suppl 2):95-102.

6 Staufenbiel SM, Penninx BW, Spijker AT, et al. Hair cortisol, stress exposure, and mental health in humans: a systematic review. Psychoneuroendocrinology 2013;38:1220-35.

7 Beals KA, Manore MM. Disorders of the female athlete triad among collegiate athletes. Int J Sport Nutr Exerc Metab 2002;12:281-93.

8 Weigand S, Cohen J, Merenstein D. Susceptibility for depression in current and retired student athletes. Sports Health 2013;5:263-6.

9 Lindqvist AS, Moberg T, Ehrnborg C, et al. Increased mortality rate and suicide in Swedish former elite male athletes in power sports. Scand J Med Sci Sports 2014;24:1000-5.

10 Huang JH, Jacobs DF, Derevensky JL, et al. Gambling and health risk behaviors among US college student-athletes: findings from a national study. J Adolesc Health 2007:40:390-7.

11 Weinstock J, Whelan JP, Meyers AW, et al. Gambling behavior of student-atheltes and a student cohort: what are the odds? J Gamb/ Stud 2007;23:13-24.

12 Wolanin A, Gross M, Hong E. Depression in athletes: prevalence and risk factors. Curr Sports Med Rep 2015;14:56-60.

13 Glazer JL. Eating disorders among male athletes. Curr Sports Med Rep 2008;7:332-7.

14 Nattiv A, Loucks AB, Manore MM, et al., American College of Sports Medicine position stand. The female athlete triad. Med Sci Sports Exerc 2007;39:1867-82.

15 Nattiv A, Puffer JC, Green GA. Lifestyles and health risks of collegiate athletes: a multi-center study. Clin J Sports Med 1997;7:262-72.

16 Yang J, Peek-Asa C, Corlette JD, et al. Prevalence of and risk factors associated with symptoms of depression in competitive collegiate student athletes. Clin J Sport Med 2007;17:481-7.
17 Proctor SL, Boan-Lenzo C. Prevalence of depressive symptoms in male intercollegiate student-athletes and nonathletes. J Clinical Sport Psych 2010;4:204-20.

18 Hammond T, Gialloreto $C$, Kubas $\mathrm{H}$, et al. The prevalence of failure-based depression among elite athletes. Clin J Sport Med 2013;23:273-7.

19 Smith AM. The psychological effects of sports injuries. Coping. Sports Med 1990:9:352-69.

20 American College of Sports Medicine, American Academy of Family Physicians, American Academy of Orthopaedic Surgeons, et al. Psychological issues related to injury in athletes and the team physician: a consensus statement. Med Sci Sports Exerc 2006:38:2030-4.

21 Wiese-Bjornstal EM. Psychology and socioculture affect injury risk, response and recovery in high-intensity athletes: a consensus statement. Scan J Med Sci Sports 2010;20(Suppl 2):103-11.

22 Walker N, Thatcher J, Lavallee D. Psychological responses to injury in competitive sport: a critical review. J of Royal Soc Promot Health 2007;127:174.

23 Nippert AH, Smith AM. Psychological stress related to injury and impact on sport performance. Phys Med Rehabil Clin N Am 2008;19:399-418.

24 Williams JM, Andersen MB. Psychological antecedents of sport and injury: review and critique of the stress and injury model. J App/ Sport Psychol 1998;10:5-25.

25 Ivarsson $A$, Johnson $U$, Lindwall $M$, et al. Psychosocial stress as a predictor of injury in elite junior soccer: a latent growth curve analysis. I Sci Med Sport 2014:17:366-70

26 Kerr G, Goss J. The effects of a stress management program on injuries and stress levels. J App/ Sport Psychol 1996;8:109-17.

27 Perna FM, Antoni MH, Baum A, et al. Cognitive behavioral stress management effects on injury and illness among competitive athletes: a randomized clinical trial. Annals Behav Med 2003;25:66-73.

28 Gerber M, Kalak N, Lemola S, et al. Are adolescents with high mental toughness levels more resilient against stress?. Stress Health 2013;29:164-71.

29 Hjemdal O, Vogel PA, Solem S, et al. The relationship between resilience and levels of anxiety, depression and obsessive-compulsive symptoms in adolescents. Clin Psychol Psychother 2011;18:314-21.

30 Brewer BW, Petrie TA. A comparison between injured and uninjured football players on selected psychological variables. Acad Athl J 1995;10:11-18.

31 Appaneal RN, Rockhill-Levine BR, Perna FM, et al. Measuring post-injury depression among male and female competitive athletes. I Sport Exerc Psych 2009:31:60-76.

32 Leddy MH, Lambert MJ, Ogles BM. Psychological consequence of athletic injury among high-level competitors. Research Quarterly Exerc Spor. 1994;65: 347-54.

33 Herring $S A$, Kibler WB, Putukian $M$, et al. The team physician and the return to play decision: a consensus statement-2012 update. Med Sci Sports Exerc 2012;44:2446-8.

34 Ardern CL, Taylor NF, Feller JA, et al. A systematic review of the psychological factors associated with returning to sport following injury. Br J Sport Med 2013:47:1120-6.

35 Wiese-Bjornstal DM, Smith AM, Shaffer SM, et al. An integrated model of response to sport injury: psychological and sociological dynamics. J App/ Sport Psychol 1998; 10:46-69.

36 Miller BE, Miller MN, Verhegge $\mathrm{R}$, et al. Alcohol misuse among college athletes: self medication for psychiatric symptoms? J Drug Educ 2002;32:41-52.

37 Smith AM, Milliner EK. Injured athletes and the risk of suicide. J Ath/ Train 1994;29:337-41.

38 McGuine TA, Winterstein A, Carr K, et al. Changes in self reported knee function and health-related quality of life after knee injury in female athletes. Clin J Sport Med 2012;22:334-40

39 Valovich McLeod RC, Bay RC, Parsons JT, et al. Recent injury and health-related quality of life in adolescent athletes. J Ath/ Train 2009;44:603-10.

40 Mainwaring LM, Hutchison M, Bisschop SM, et al. Emotional response to sport concussion compared to ACL injury. Brain Inj 2010;24:589-97.

41 http://sportsillustrated.cnn.com/vault/article/magazine/MAG1029764/index.htm (accessed 26 Nov 2013).

42 McCrory P, Meeuwisse W, Aubry M, et al. Consensus statement on concussion in sport-the 4th International Conference on Concussion in Sport held in Zurich, November, 2012. Clin J Sport Med 2013;23:89-117.

43 Herring S, Cantu R, Guskiewicz KM, et al. Concussion (mild traumatic brain injury) and the team physician: a consensus statement. Med Sci Sports Exerc 2011:43:2412-22.

44 Harmon K, Drezner JA, Gammons M, et al. American Medical Society for Sports Medicine position statement: concussion in sport. Br J Sport Med 2012;47:15-26.

45 McCrory P, Meeuwisse WH, Echemendia RJ, et al. What is the lowest threshold to make a diagnosis of concussion?. Br J Sport Med 2013;47:268-71.

46 Gardner A. The complex clinical issues involved in an athlete's decision to retire from collision sport due to multiple concussions: a case study of a professional athlete. Front Neurol 2013:4:141.

47 Makdissi M, Davis G, Jordan B, et al. Revisiting the modifiers: how should the evaluation and management of concussions differ in specific groups?. Br J Sport Med 2013;47:314-20. 
48 Guskiewicz KM, Marshall SW, Bailes J, et al. Recurrent concussion and risk of depression in retired professional football players. Med Sci Sports Exerc 2007;39:903-9.

49 Kerr ZY, Marshall SW, Harding HP, et al. Nine-year risk of depression diagnosis increases with increasing self-reported concussions in retired professional football players. Am J Sports Med 2012;40:2206-12.

50 McCrory P, Meeuwisse WH, Kutcher JS, et al. What is the evidence for chronic concussion-related changes in retired athletes: behavioural, pathological and clinical outcomes? Br J Sport Med 2013;47:327-30.

51 Karantzoulis S, Randolph C. Modern chronic traumatic encephalopathy in retired athletes: what is the evidence?. Neuropscyhol Rev 2013;23:350-60.

52 Hazrati LN, Tartaglia MC, Diamandis P, et al. Absence of chronic traumatic encephalopathy in retired football players with multiple concussions and neurological symptomatology. Front Hum Neurosci 2013;7:222.

53 Gulliver A, Griffiths KM, Christensen $\mathrm{H}$, et al. Internet-based interventions to promote mental health help-seeking in elite athletes: an exploratory randomized controlled trial. J Med Internet Res 2012;14:e69.

54 Gulliver A, Griffiths KM, Christensen H. Barriers and facilitators to mental health help-seeking for young elite athletes: a qualitative study. BMC Psychiatry 2012;12:157.

55 Neal TL, Diamond AB, Goldman S, et al. Inter-Association recommendations for developing a plan to recognize and refer student-athletes with psychological concerns at the collegiate level: an executive summary of a consensus statement. J Athl Train 2013;48:716-20.
56 Neal TL, Diamond AB, Goldman S, et al. Interassociation recommendations for developing a plan to recognize and refer student-athletes with psychological concerns at the secondary school level: a consensus statement. J Ath Train 2015;50:231-49.

57 National Collegiate Athletic Association. 2013-2014 sports medicine handbook. http://www.ncaapublications.com/p-4328-2013-14-ncaa-sports-medicinehandbook.aspx (accessed 26 Nov 2013).

58 National Collegiate Athletic Association. Managing student-athletes' mental health issues. http://www.princeton.edu/uhs/pdfs/NCAA\%20Managing $\%$ 20Student-Athletes\%20Mental\%20Health\%20lssues.pdf (accessed 26 Nov 2013).

59 Hamson-Utley JJ, Martin S, Walters J. Athletic trainers' and physical therapists' perceptions of the effectiveness of psychological skills within sport injury rehabilitation programs. J Athlet Train 2008;43:258-64.

60 http://www.ncaa.org/health-and-safety/sport-science-institute/preventionprogramming

61 http://stepupprogram.org/

62 http://uhs.princeton.edu/medical-services/athletic-medicine/varsity-student-athletewellness-resources

63 Spitzer RL, Kroenke K, Williams JB, et al. A brief measure for assessing generalized anxiety disorder: the GAD-7. Arch Intern Med 2006;166:1092-7.

64 Kroenke K, Spitzer R, Williams W. The PHQ-9: validity of a brief depression severity measure. J Gen Intern Med 2001;16:606-16.

65 Putukian M, Echemendia R, Dettwiler-Danspeckgruber A, et al. Prospective clinical assessment using Sideline Concussion Assessment Tool-2 testing in the evaluation of sport-related concussion in college athletes. Clin J Sport Med 2015;25:36-42. 